\title{
Vibrotactile letter recognition: The effects of a masking stimulus
}

\author{
JAMES C. CRAIG \\ Indiana University, Bloomington, Indiana 47401
}

\begin{abstract}
A series of experiments examined the effect of masking stimuli on the ability of observers to recognize letters of the alphabet through their fingertips. The letters were generated on the $6 \times 24$ vibrotactile array of the Optacon, a reading aid for the blind. Letter recognition was interfered with by the presence of masking stimuli occurring at the same site on the skin either before (forward masking) or after (backward masking) the target letter had been presented. In general, backward masking interfered with letter recognition more than did forward masking. Backward masking was particularly effective for letters in which the information critical for identification is located on the right side of the letter. Presenting the letters reversed resulted in more forward masking for those letters with critical information now located on the left side. Increasing the time between the target letter ard the masking stimuli resulted in improved letter recognition. The implications of the results for tactile reading are discussed.
\end{abstract}

The topic of letter recognition through the skin is of potential interest to several diverse areas of investigation. From the standpoint of creating a sensory aid for the blind, it would be very useful to understand some of the basic problems in rapid, tactile letter recognition. Already commercially available to the blind is a device that converts ordinary printed material to patterns of vibration that can be felt and interpreted by the user. With this device, called the Optacon, ${ }^{1}$ a number of blind people have learned to read ordinary print. Trained users of the Optacon can expect to achieve reading rates between 30 and 60 words $/ \mathrm{min}$, rates which are approximately half of the braille reading rates of those users who read braille regularly (Goldish \& Taylor, 1974). When users have achieved high reading rates with the Optacon, 5 to 6 letters/sec are being presented. Under such conditions, it might well be expected that the letters would exert mutual influence on one another, perhaps making it more difficult to recognize the letters in combination than letters in isolation. Such difficulty in correctly identifying letters in the presence of other stimuli we will refer to as "masking." One of the purposes of the present study was to see the extent to which and under what conditions such masking might occur.

The previously published studies on vibrotactile masking have employed, for the most part, a detection paradigm. In these studies, the threshold for detecting a stimulus is typically measured in the absence of any other stimuli and then in the presence

This study was supported by Grant NS 09783 from the National Institutes of Health, U.S. Department of Health, Education, and Welfare. of some extraneous (masking) stimulus. The-difference in the amplitude required to detect the stimulus in the absence of and in the presence of the masking stimulus is defined as the amount of threshold elevation (Gilson, 1969) or as the amount of masking (Craig, 1972; Sherrick, 1964). The studies of vibrotactile masking have certainly demonstrated that one vibrotactile stimulus can interfere with the detection of another stimulus and that the two stimuli need not be spatially and/or temporally contiguous (Békésy, 1960; Craig, 1976; Gilson, 1969; Sherrick, 1964). The extent to which variables that affect detection in a masking paradigm also affect recognition of letters was one question to which the present study was addressed.

Loomis and Apkarian-Stielau (Note 1) studied tactile recognition accuracy for letters presented using two columns of a $20 \times 20$ array of vibrators placed against a subject's back. They reported that letter recognition was interfered with by the presence of simultaneous masking stimulation. The masking stimulation consisted of parallel columns of vibrators being energized on both sides of the area where the letter was displayed. Increasing the separation between the letter and the masking stimuli improved letter recognition accuracy. They concluded that tactile lateral masking was a consequence of the limited spatial resolution of the skin.

Very recently there has appeared a paper by Schindler and Knapp (1976) that examined recognition masking of letters presented to the fingertips. Using an Optacon-like display, subjects were presented pairs of letters drawn from a sample of five letters: "J, L, T, C," and "V." The subjects were asked to identify the two letters in the order in which they were presented. The main emphasis of the study was to test models of masking. A number of pro- 
cedural differences between the present study and the Schindler and Knapp study makes it difficult to compare the two studies directly. However, the results of the present study, particularly those of Experiment 2, are relevant for the kinds of errors that are made in recognition masking studies, and the results of Experiment 4 are in agreement with a similar manipulation Schindler and Knapp performed.

The present study was concerned with the general problem of vibrotactile letter recognition and with the specific influence that potential masking stimuli have on letter recognition. The masking stimuli consisted of patterns of vibration presented to the same area of skin to which the letter was presented either before or after the letter had been presented. The present study was not undertaken with the explicit purpose of comparing tactile to visual letter recognition and the effect that masking stimuli have on such processes nor with testing particular models of masking. However, the present results may prove useful to investigators who are interested in comparing such processes across modalities or who are interested in models of masking.

\section{EXPERIMENT 1}

In the first experiment, we were concerned simply with what effect the spatial position of a letter within a "word" would have on recognition of that letter. Specifically in a trigram, in what position would it be easiest to recognize a letter-first, second, or third? If masking of the letter is a significant problem in letter recognition, it would be expected that letters placed in the middle position would be most difficult to identify, letters in that position being potentially subject to both forward and backward masking. The relative difficulty in identifying letters in the first and third positions would seem to depend on the effectiveness of backward and forward masking, respectively.

\section{Method}

Observers. The observers, two men and two women, were paid laboratory personnel. They had all passed a screening test with the Optacon before being employed. Prior to their participation, the observers had previous experience with a discrimination task with stimuli similar to those employed in Experiment 1.

Apparatus. The device used to generate the patterns of vibration was the Optacon. The Optacon, a reading aid for the blind, consists of a camera that registers the patterns of black and white produced by a letter on a 144-element, optical array. The optical array is 6 columns wide $\times 24$ rows high. The pattern produced by a letter on the optical array is transmitted to a 144element, tactile array. The tactile array is also 6 columns by 24 rows, with the spacing between columns being greater than that between rows. The array consists of pins that vibrate at $230 \mathrm{~Hz}$ when light is cut off from one element of the camera. The letter " $O$," for example, passing beneath the camera will result in a circular pattern of vibration on the array. In using the device, a person places his left index finger on the vibrating array, which is $1.14 \mathrm{~cm}$ wide $\times 2.72 \mathrm{~cm}$ high. As the camera is moved across a letter from left to right, the person feels a pattern of vibration begin on the right side of his index finger and move across to the left side of his finger.

The Optacon has controls for changing the magnification of the camera to adjust for different sizes of letters. There is also an adjustment that controls the amount of contrast required to trigger the photosensitive elements and, consequently, the vibrating array.

In normal use, the user moves the camera across the material to be read. In the present experiments, the camera was moved on an Automatic Page Scanner (APS) across the patterns. The APS, also manufactured by Telesensory Systems, Inc., is a modified $x-y$ plotter. It provides for a controlled, smooth rate of movement of the camera across the patterns to be identified.

Procedure. The stimuli employed were uppercase letters of the alphabet. The letters were typed with a Dual Gothic typing ball and an IBM Selectric typewriter. The Dual Gothic typing ball produces a block-like, sans-serif letter.

Lists of randomly selected trigrams were presented to the observers. All 26 letters of the alphabet were used. At the beginning of each list of 40 trigrams, the observer was told that he/she was to identify the letter appearing in a particular position in the trigram-first, second, or third position. Following each trigram, the observer responded by indicating which letter he/she thought was in the requested position. After each trial, the observer was told what the correct response was.

The lists of trigrams were placed on the APS with the rate set at 46 words/min (wpm). For the stimuli employed, this rate results in the leading edge of a letter (or any edge for that matter) being displayed for a total of $170 \mathrm{msec}$. The time between adjacent letters in the trigrams was, on the average, approximately $50 \mathrm{msec}$. The time between two "I"s would be greater than the time between two "W"s. The magnification adjustment on the Optacon was set so that the average letter, when centered beneath the camera, would occupy the top 18 rows of the Optacon display and all 6 columns of the display. The size of the average letter as displayed on the observer's finger was approximately $1.1 \times 2.0 \mathrm{~cm}$. The sensitivity of the Optacon was adjusted so that the horizontal strokes of a letter would trigger two rows of vibrating pins, whereas the vertical strokes would trigger one column. The amplitude of vibration was adjusted to a "comfortable" level for each observer.

In a typical testing session, the observers would receive $\mathbf{1 2 0}$ trials. The trials were grouped in blocks of 40 . During a 40 -trial block, the observer would be required to identify the same position-first, second, or third.

Throughout the testing session, the observers wore goggles and earphones through which white noise was fed. The purpose of the white noise was to minimize any auditory cues produced by the Optacon vibratory display.

\section{Results and Discussion}

Each observer was tested for a total of 320 trials at each position. The mean percent correct at each position for each observer is shown in Figure 1. Figure 1 also shows the overall mean results based on 1,280 trials per point. As may be seen, the four observers showed a similar pattern of responding, viz, the third position was the easiest, first position next, and the middle position the most difficult. Bliss and Linvill (1967) studied letter recognition with a $6 \times 8$ array of airjets on the hand. In the course of one experiment, their subjects were presented three letters in close temporal proximity. In agreement with the results of the present experiments, the 


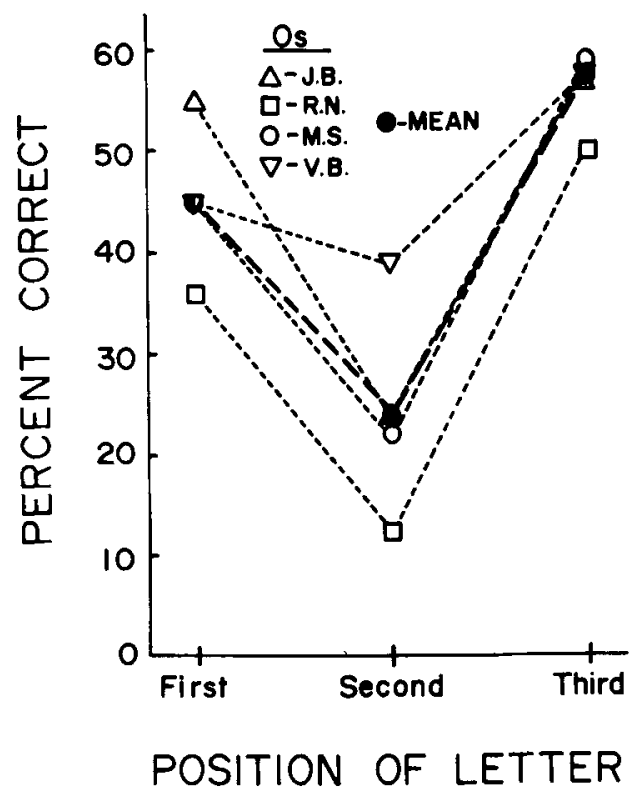

Figure 1. Percent correct recognition of target letters as a function of the position of the letter in a trigram. The individual observer's data and the group mean data are shown.

subjects had a great deal of difficulty identifying the second of the three letters presented.

These results do not represent asymptotic performance. The observers showed a general improvement throughout the course of the experiment. The mean percent correct across observers and letter positions for the first 480 trials was $32 \%$. The mean percent correct across observers for the final 480 trials was $40 \%$. However, throughout the period of the experiment, the observers continued to show the same ordering of percent correct responses, i.e., third, first, and second position.

The results suggest that conditions that might be expected to result in masking, presenting an extraneous stimulus before and after a target stimulus, do lead to considerable decrements in letter recognition. Also, from the consistent finding that the first letter in the trigram was more difficult to identify than the third, it appears that backward masking is more effective than forward masking in disrupting letter recognition under these conditions.

\section{EXPERIMENT 2}

The results from Experiment 1 did not include a condition in which observers were required to identify a single letter in the absence of any potential masking stimulus. It is not possible to state that there was any forward masking in Experiment 1. It is possible that single-letter recognition, i.e., presenting a single letter without either a forward or a backward masker, could be equivalent to recognition of letters appearing in the third position. One purpose of Experiment 2 was to measure single- letter recognition accuracy and compare it to recognition of letters immediately following a masker.

A second question Experiment 2 addressed was whether or not it was necessary to have letters serve as masking stimuli. Letter recognition might be interfered with because of similarity in shape between maskers and targets. It is also possible that the letters may have served as maskers in Experiment 1 because they sweep a pattern of vibration across the same locus as the target occupies, and the masking effect is independent of the particular masker employed. Experiment 2 compared letter recognition in the presence of both letters and nonletters employed as masking stimuli.

\section{Method}

Observers. Three of the four observers from Experiment 1 were tested in Experiment 2. Two of the observers were men. One observer was a woman.

Apparatus. The same apparatus employed in Experiment 1 was used in Experiment 2.

Procedure. Two conditions were tested in the experiment. In the first condition, the observers were asked to identify letters of the alphabet presented either by themselves or in the presence of masking stimuli. The masking stimulus employed was a black rectangle the same height and width as the letter " $N$ " or the letter "H." The effect of the masker was to turn on all the vibrators in the same rows and columns of the vibratory matrix and for the same duration as the average letter. The following arrangements of masking stimuli were tested: one with the masker preceding the target letter (forward masking), one with the masker following the target (backward masking), and one with maskers placed both before and after the target (double). The various masker conditions and a single-letter condition were run in 40-trial blocks. An attempt was made to test each condition in a random order during each testing session. The rate on the APS was set at $46 \mathrm{wpm}$. A single edge of a letter was displayed for $170 \mathrm{msec}$. The time between the average letter and the masker was $50 \mathrm{msec}$. The other specifics of 'the procedure were similar to those of Experiment 1.

In the second condition of the experiment, the observers were tested on single-letter recognition and with two different types of masking stimuli. One masking stimulus was a pair of letters, identical to the trigrams in Experiment 1. The other masking stimulus was a pair of black rectangles, identical to the masking stimuli used in the first condition of Experiment 2. Both the letters that served as masking stimuli and the target letters were selected randomly. The three stimulus configurations were tested in 40-trial blocks. The rest of the procedure was the same as that in the first condition of Experiment 2.

\section{Results and Discussion}

The data from the first condition of Experiment 2 are shown in Figure 2. Each point for each observer represents the mean percent correct from 200 trials. Each point in the group means, therefore, represents 600 trials. It is clear that single-letter recognition, i.e., presenting the letter with no masking stimuli, is superior to all the masking conditions. Forward masking does appear to interfere with letter recognition, although not to the same extent as does backward masking. It also appears that the effects on letter recognition of a forward and a backward masker are cumulative. Presenting both a forward 


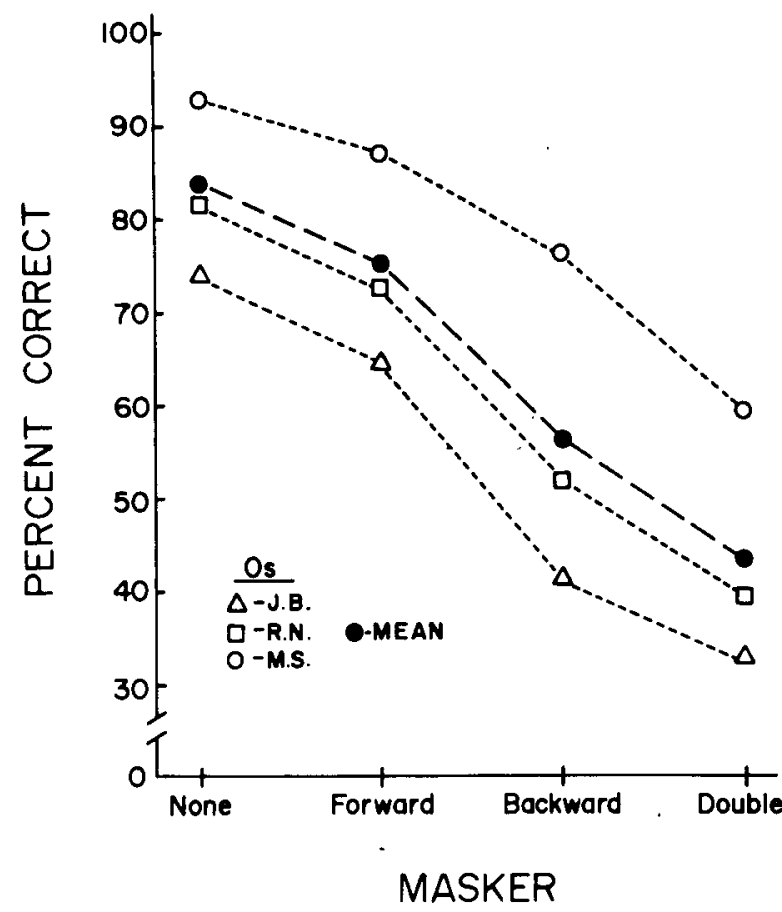

Figure 2. Percent correct recognition of target letters as a function of the nature of the masking stimulus. "None" means no masking stimulus was used. "Forward" means a masking stimulus came on prior to the target letter. "Backward" means a masking stimulus came on after the target letter. "Double" means masking stimuli came on both before and after the target letter. The individual observer's data and the group mean data are shown.

and a backward masker reduces letter recognition below that of the backward masker alone.

The above results from the first condition also demonstrate that letter maskers are not necessary for the reduction of letter-recognition accuracy. The results from the second condition of the experiment, shown in Figure 3, indicate the relative effectiveness of a letter masker vs. a nonletter masker. Each point for each observer represents the mean percent correct for 240 trials. It can be seen that the observers' performances are slightly poorer overall in this condition than in the first condition of the experiment. The second condition of the experiment was, in fact, tested prior to the first condition, and observers appeared to show some improvement over time.

The results do not suggest a clear advantage for either letters or nonletters as masking stimuli. It is the case that with the rectangles as maskers the observers always received the same stimulus before and after the target letter. When the letter maskers were used, different letters surrounded the target letter on each trial. The argument could be made that, had the same two letters been employed as maskers throughout the experiment, the observers might have done better than they did with different letters as maskers. Additional measurements with the same letters used throughout the experiment would be necessary to see whether there would be considerable improvement in recognition accuracy. The reason for using different letters in the present experiment was to parallel the conditions encountered in reading.

In the Schindler and Knapp (1976) study referred to above, many of the errors that the subjects made were the result of responding with the "correct" letter in the wrong position. For example, presented " JL," the subject might respond "LJ." Such errors were important in the testing of one of the models of masking that the authors proposed. The fact that a large number of such exchange errors occurred might lead one to suppose that in the present experiment letters would be more effective than the black rectangles in interfering with letter recognition. In fact, an analysis of the responses in the present study show that such exchange errors were not particularly common. It would be expected that by chance exchange errors in the present study should be about $2 / 25$, or $8 \%$, i.e., the observer is presented three letters, incorrectly identifies the target letter, and responds with one of the remaining 25 letters, two

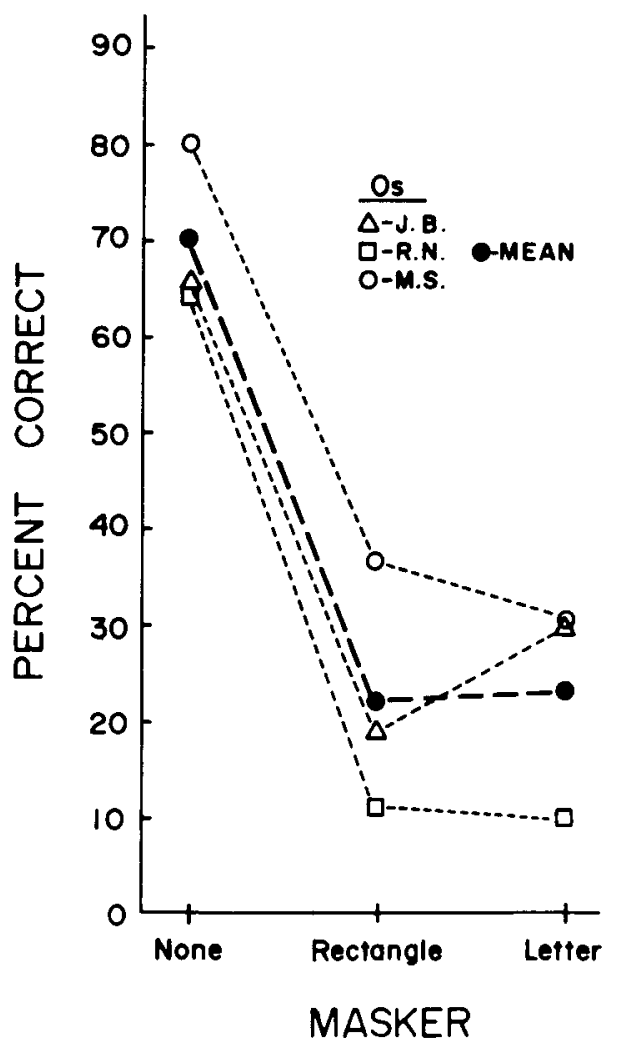

Figure 3. Percent correct recognition of target letters as a function of the nature of the masking stimuli. "None" means no masking stimulus was used. "Rectangle" means black rectangles were presented before and after the target letter. "Letter" means letters were presented before and after the target letter. The individual observer's data and the group mean data are shown. 
of which have been presented in addition to the target letter. The rate of exchange errors with the letters serving as masking stimuli was rather low, $15 \%$. A similar calculation on the data from Experiment 1 showed an even lower exchange error rate, $13 \%$. With so few of the errors resulting from observers responding incorrectly with one of the two letters presented, it is probably not surprising that rectangles were as effective as letters as masking stimuli. Schindler and Knapp did find, however, that exchange errors increased as the time interval between target and masker decreased. It is likely that, had shorter times between target and masker been examined in the present study, more exchange errors would have been found and perhaps more masking would have been obtained with letters than with rectangles.

Up to this point, the results have been discussed in terms of the effect of a forward and a backward masker. Such a discussion implies that the key factor is the temporal relationship between masker and target and that a backward masker is more effective than a forward masker because it follows the target in time. However, another explanation is possible. The presentation of the target and masker in the present experiments is somewhat unusual in that the target moved across the tactile array from right to left and was, in the backward-masking condition, followed by a masking stimulus also moving from right to left. The right side of the letters, the trailing edge, was therefore followed very closely in time by the left side of the masking stimulus, the leading edge. Also, a number of the uppercase letters have most of the information critical for identification on the right side of the letter. Specifically, these letters are "B, C, D, E, F, G, K, L, P, Q," and "R." The remaining uppercase letters of the alphabet are more or less symmetrical, with the exception of " $J$," and can be identified from the information on the left half or the right half of the letters. What appears to be more effective backward than forward masking may be the result of the close temporal (and possibly spatial) proximity of the masker which follows the target to the critical features of some letters, the "right-hand letters." Two questions may be asked of the data. First, was the recognition of the "right-hand letters" ( $R$ letters) degraded more by a backward masker than were the "symmetrical letters" (S letters). Second, if the R letters are removed from the analysis of the data, is there still a difference between the backward and the forward masking conditions?

In order to compare results across letters, the average percent correct for the $\mathrm{R}$ letters and for the $S$ letters was calculated for the no, forward, backward, and double masking conditions in the experiment. These calculations are shown in Table 1 . (Because the lists of letters tested were generated
Table 1

Percent Correct Recognition for R Letters and S Letters Under Various Masking Conditions: Normal Presentation

\begin{tabular}{lcccc}
\hline & $\begin{array}{c}\text { No } \\
\text { Masker }\end{array}$ & $\begin{array}{c}\text { For- } \\
\text { ward }\end{array}$ & $\begin{array}{c}\text { Back- } \\
\text { ward }\end{array}$ & Double \\
\hline R Letters & 87 & 80 & 53 & 45 \\
S Letters & 84 & 71 & 58 & 43 \\
\hline
\end{tabular}

randomly, there was an unequal number of presentations of each letter. The percent correct shown in Figure 2 is based on the total number of trials. The average percent correct for the various letter groups will not necessarily be equal to the total percent correct.) It appears that, in fact, the letters are affected more by a backward masking stimulus than are the $S$ letters as measured by either the change from single-letter recognition or from the forward masking condition to the backward masking condition. There was a significantly greater decrease in recognition in going from the forward to the backward masking condition for the $\mathbf{R}$ letters as compared to the $S$ letters $(\mathrm{p}<.05$, one-tail, Mann-Whitney $U$ test). It also appears that, even with the $R$ letters removed from the analysis, there is still more backward than forward masking. Of the $15 \mathrm{~S}$ letters, only 4 showed more forward than backward masking.

It might also be expected that a forward masker, temporally removed from the critical information in $R$ letters, would not have a large effect on the $R$ letters. The data show that a forward masker reduced correct recognition only $7 \%$ for the $R$ letters, whereas the forward masker reduced correct recognition $13 \%$ for the $S$ letters.

\section{EXPERIMENT 3}

Although the post hoc analysis of the letters according to right-hand vs. symmetrical groupings showed a differential effect for forward and backward masking, a more convincing demonstration of the importance of the location of critical information in the letters might be to reverse the effect of the masking conditions. The most straightforward way of reversing the effect would seem to be to reverse the letters. For the majority of the $S$ letters, reversal does not change the appearance of the letter. For the remainder of the S letters, specifically " $\mathrm{J}, \mathrm{N}, \mathrm{S}$," and ' $\mathrm{Z}$," there would be some change in their appearance when reversed. Reversing the $R$ letters, of course, produces a much more radical change in their appearance. For our purposes, the important change is that the critical information for letter recognition would be located on the lefthand side of the letter. In short, the critical information would be closer in time to the forward than to the backward masker.

The following predictions can be made. First, backward masking should be less effective than 
forward masking for the reversed $\mathrm{R}$ letters. Second, the $\mathrm{S}$ letters should continue to show more backward than forward masking.

\section{Method}

Observers. The three observers tested in Experiment 2 were tested in Experiment 3.

Apparatus. The same apparatus employed in Experiment 2 was used in Experiment 3.

Procedure. The conditions tested were similar to those tested in the first condition of Experiment 2. In blocks of 40 trials, observers were presented a single letter, a letter preceded by a masker (black rectangle), a letter followed by a masker, and a letter preceded and followed by maskers. The only difference between the first condition of Experiment 2 and Experiment 3 was that the target letters were printed backwards. As before, the rate of presentation was $46 \mathrm{wpm}$, which meant that any point on a letter required $170 \mathrm{msec}$ to cross the display.

\section{Results and Discussion}

The mean results for each observer and the overall mean are shown in Figure 4 . Each point for each observer is the result of 200 trials. The overall mean is based on 600 trials per point. It still appears that a forward masker is less effective in reducing letter recognition than is a backward masker, although the difference between the two conditions is much smaller than it was in Experiment 2.

The reason that the difference between forward and backward masking is reduced may be seen when the data are analyzed according to R-letter and Sletter groups. Bearing in mind that the $\mathrm{R}$ letters were reversed in Experiment 3 and, therefore, the in-

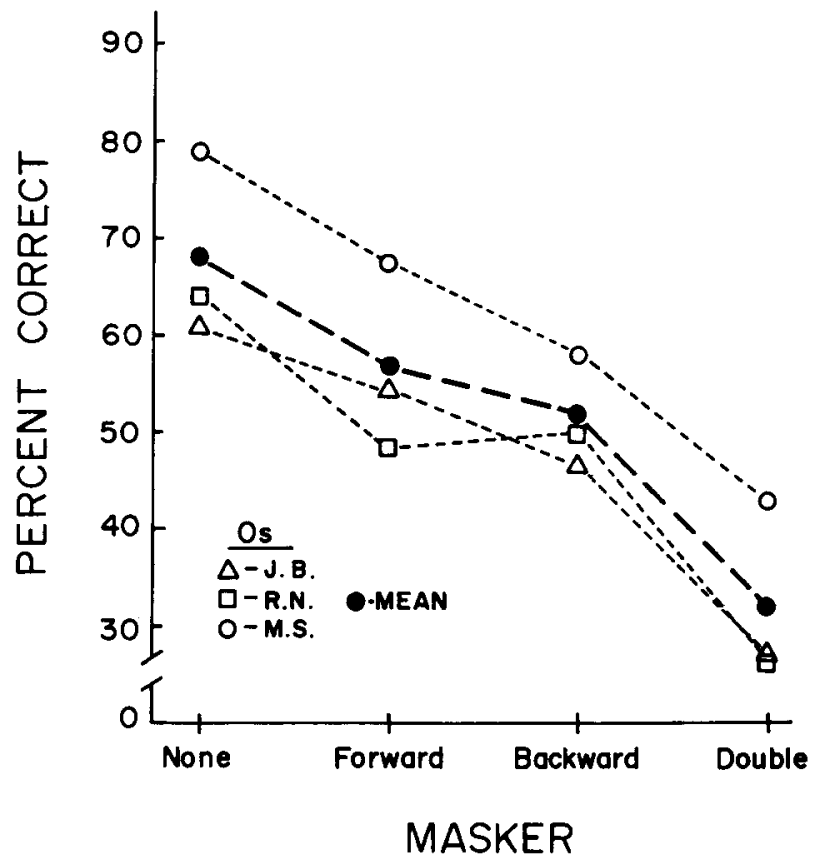

Figure 4. Percent correct recognition of reversed target letters as a function of the nature of the masking stimuli. Axes labeled as in Figure 2. The individual observer's data and the group mean data are shown.
Table 2

Percent Correct Recognition for $\mathbf{R}$ Letters and $\mathbf{S}$ Letters Under Various Masking Conditions: Reversed Presentation

\begin{tabular}{lcccc}
\hline & $\begin{array}{c}\text { No } \\
\text { Masker }\end{array}$ & $\begin{array}{c}\text { For- } \\
\text { ward }\end{array}$ & $\begin{array}{c}\text { Back- } \\
\text { ward }\end{array}$ & Double \\
\hline R Letters & 55 & 36 & 46 & 29 \\
S Letters & 73 & 67 & 54 & 37 \\
\hline
\end{tabular}

formation critical for their recognition would be located on the left side of the letter, it would be predicted that a forward masker would be more effective in reducing recognition of the $R$ letters than would a backward masker. The results shown in Table 2 support the prediction. For the $\mathrm{R}$ letters, not only did a backward masker not reduce letter recognition when compared to the effect of a forward masker, but the average recognition per letter increased by $10 \%$ between the two conditions. The $\mathrm{S}$ letters, as in Experiment 2, continued to show a greater decrement in recognition in the presence of a backward as compared to a forward masker. There was a significantly greater decrease in recognition (increased masking) in going from the forward to the backward masking condition for the $S$ letters as compared to the $R$ letters $(p<.025$, one-tail, Mann-Whitney U test). (For purposes of this analysis, the letter " $D$ " was not included because of the very few times, three, that it was presented in the backward masking condition.) It should be recalled that the reverse was true in Experiment 2, i.e., a greater decrease for $\mathbf{R}$ letters as compared to $\mathbf{S}$ letters in going from the forward to the backward masking condition.

The finding that reversing the $\mathrm{R}$ letters makes a forward masker more effective than a backward masker is supported by the observation that in Experiment 2, with the letters presented in the normal way, 10 out of $11 \mathrm{R}$ letters showed more backward than forward masking. With the letters reversed, 7 out of 11 showed more forward than backward masking. For the $\mathrm{S}$ letters, normal presentation resulted in 12 out of 15 letters showing more backward than forward masking, and, in the reversed condition, 11 out of 15 letters also showed more backward than forward masking.

Although a forward masker is more effective for some letters when these letters are reversed, the overall finding from Experiments 2 and 3 is that backward masking reduces letter recognition more than does forward masking. This result seems consistent with results with auditory and visual stimuli when recognition of the stimuli was the dependent measure (Massaro, 1975). In the studies that have examined detection of vibrotactile stimuli in the presence of vibrotactile maskers, there does not appear to be a clear-cut advantage for either forward or backward masking (Gilson, 1969; Sherrick, 1964). Rollman (1974) has found greater backward than forward 
masking using a pulse as the test stimulus and an electrocutaneous stimulus as the masker. Even though the observers had difficulty recognizing the letters, they had no difficulty in perceiving that the target letter had occurred, i.e., they had no difficulty detecting the target. It would not, however, be surprising if recognition masking paralleled detection masking in that the same variables that are known to affect detection in a masking paradigm would also affect recognition.

\section{EXPERIMENT 4}

A key variable in studies of vibrotactile backward and forward masking has been the time between the test stimulus and the masking stimulus. For detection tasks, the typical finding has been that the longer the time interval between test and masker, the greater the detectability of the test stimulus (Gilson, 1969; Sherrick, 1964). Similarly, and not surprisingly, the general finding in recognition tasks using visual and auditory stimuli has been that increasing the time between target and masker improves recognition accuracy (Massaro, 1975). Experiment 4 examined the role of time between the masking stimuli and the target stimulus.

The time between target and masker is also of importance for the explanation offered for the difference in effectiveness of masking stimuli on $R$ letters and $S$ letters. It was reasoned that the temporal gap between the masking stimulus and the critical element of the letter was responsible for the difference in effectiveness between the forward and the backward masking stimuli. If changing the time between the target and the masker had no effect on recognition, it would make the above explanation much less plausible.

\section{Method}

Observers. The same three observers tested in Experiments 2 and 3 were tested in Experiment 4.

Apparatus. The apparatus was the same as that used in Experiments 1, 2, and 3 .

Procedure. Random lists of single letters were prepared with masking stimuli, black rectangles, placed before and after the single ietters. As before, the observer's task was to identify which one of the 26 letters of the alphabet had been presented. Feedback was given after each trial.

The observers were tested in blocks of $\mathbf{4 0}$ trials, each block consisting of a different condition of the experiment. In one condition, masking stimuli were placed adjacent to the target letters. In another condition, one letterspace intervened between the masking stimulus and the target, and, in a third condition, two letterspaces were placed between the masking stimuli and the target. Single-letter recognition, i.e., no masking stimuli, was tested in a fourth condition.

Two different scan rates were used, 46 and $92 \mathrm{wpm}$. With no letterspace between the target and the maskers, the 46-wpm rate resulted in a time of approximately $50 \mathrm{msec}$ between the offset of the trailing edge of the first masker and the onset of the leading edge of an average letter. A similar time, $50 \mathrm{msec}$, between the offset of the trailing edge of an average letter and the onset of the leading edge of the second masker was also found. With one letterspace between the maskers and the target, the time between the forward masker and the target and the backward masker and the target was $315 \mathrm{msec}$, and with two letterspaces the time was $550 \mathrm{msec}$. With the $92-\mathrm{wpm}$ scan rate, the times between target and masker for the zero-, and one-, and two-letterspace conditions were 28,160 , and $300 \mathrm{msec}$, respectively. At $46 \mathrm{wpm}$, the display time, the time that it took for one part of a letter to cross the array, was $170 \mathrm{msec}$. At $92 \mathrm{wpm}$, the display time was $90 \mathrm{msec}$.

The observers received 120 trials per condition at the 46-wpm rate. They then received 120 trials per condition at the 92-wpm rate.

\section{Results and Discussion}

The results with the $46-\mathrm{wpm}$ rate are shown in Figure 5. The results with the 92-wpm rate are shown in Figure 6. Each point for each individual observer represents the mean of 120 trials, and the points in the overall mean function represent 360 trials.

It is apparent that, for both scan rates, increasing the time between target and masker improves letter recognition. Whereas this finding is not particularly surprising, it does tend to indicate that the masking effect, the reduction in letter recognition accuracy, is due to something more than the "distraction" produced by the maskers. The result that increasing the time between the target and the masking stimuli produces a greater number of correct responses is similar to results obtained by Bliss and Linvill (1967) and by Schindler and Knapp (1976) in a letter recognition paradigm and by Gilson (1969) and

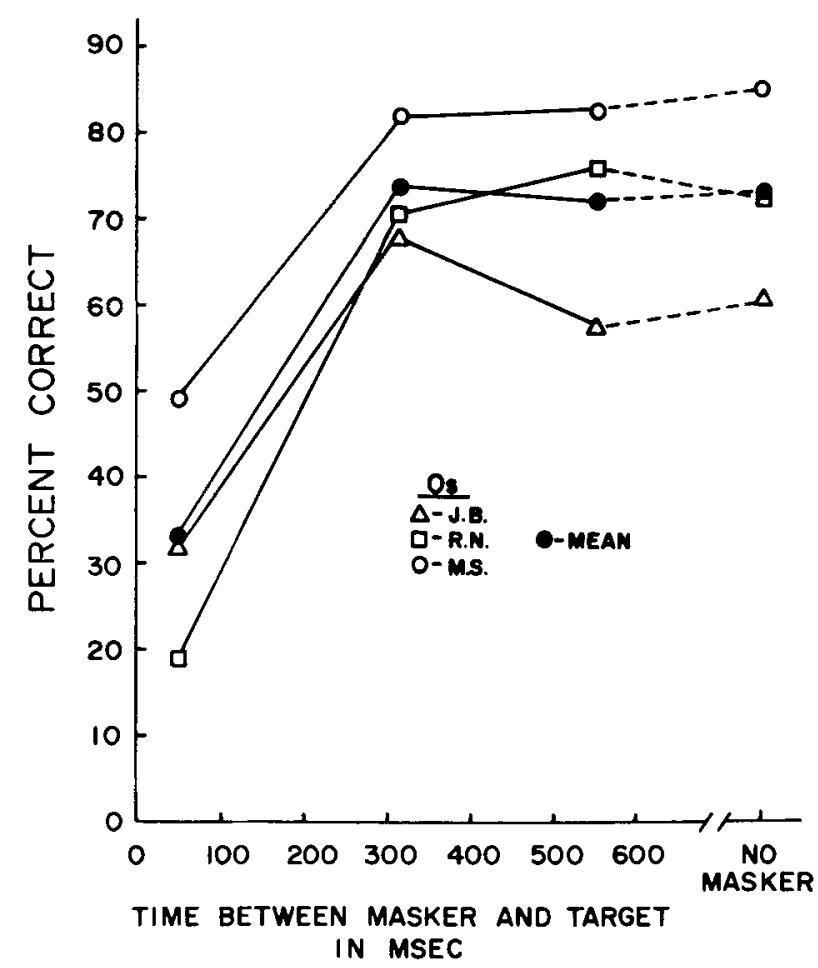

Figure 5. Percent correct recognition of target letters as a function of the time between the masking stimuli and the target letter. Display time was 170 msec. The individual observer's data and the group mean data are shown. 


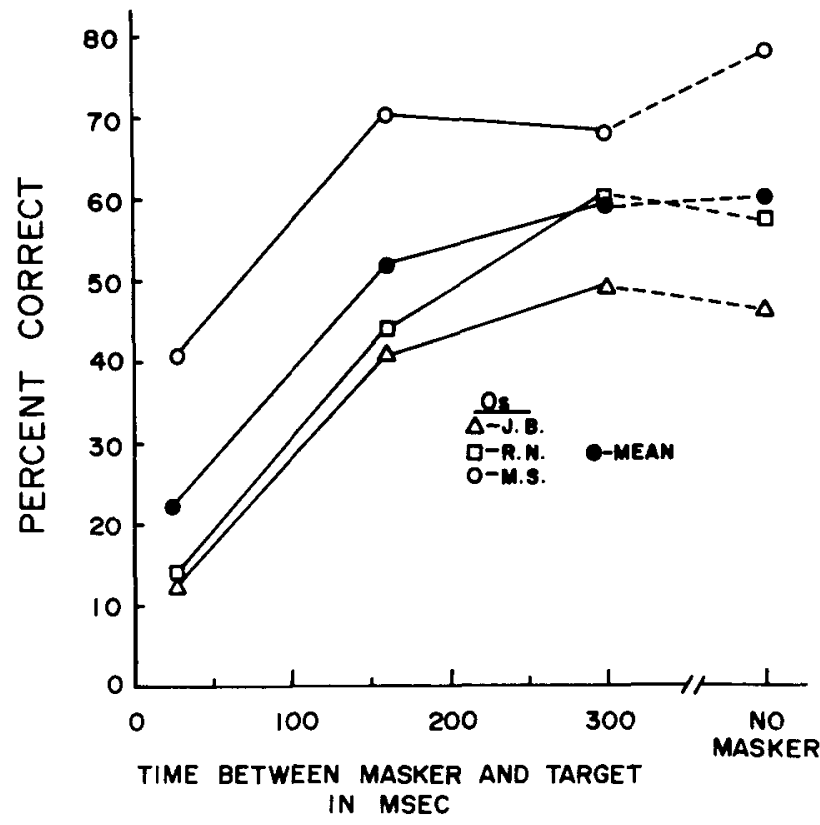

Figure 6. Percent correct recognition of target letters as a function of the time between the masking stimuli and the target letter. Display time was 90 msec. The individual observer's data and the group mean data are shown.

Sherrick (1964) in a detection paradigm. Whether or not the present results would parallel exactly those obtained in detection studies would require precise manipulation of the time between the target and the masking stimuli that the present apparatus does not permit.

In Experiment 3, it was suggested that the reason the $R$ letters when reversed were affected less by a backward masker than were the $\mathrm{S}$ letters was the increased temporal separation between the critical features of the target and the masker. The results of Experiment 4 tend to support that explanation.

Although the emphasis of the discussion has been on the temporal relationship between the masker and the target, there are spatial factors that could also be affecting letter recognition. With the masker placed as close as possible to the target, there are approximately one to two columns separating the target and the masker. Thus, one might expect that masking dependent upon the limited spatial resolution of the skin as discussed by Loomis and Apkarian-Stielau (Note 1) would also be a factor in affecting letter recognition. Such spatial proximity should also be considered, as noted above, in assessing the effectiveness of forward and backward maskers on $\mathbf{R}$ and $\mathrm{S}$ letters. Independent manipulation of the time between the masker and the target and the spacing between the masker and the target would be required to establish the relative importance of the spatial and the temporal factors.

The results from Figures 5 and 6 cannot be plotted on the same graph because of the difference in display times for the target and for the masking stimuli. It is possible to look at the "no-masker" condition and ask about the effect of display time on correct recognition. It appears that nearly halving the display time from 170 to $90 \mathrm{msec}$ results in a decrease in correct recognition from $73 \%$ to $60 \%$, a $13 \%$ decrease. The presence of masking stimuli adjacent to the target reduces correct recognition from $73 \%$ to $33 \%$ in the 46-wpm condition and from $60 \%$ to $22 \%$ in the $92-w p m$ condition. These reductions in percent correct, $40 \%$ and $38 \%$, caused by the presence of masking stimuli, appear to be considerably greater than the reduction resulting from decreasing the display time for a single letter. The relationship of scan rate to display time and masking and, in turn, the overall relationship to the process of reading are considered in the next section.

\section{GENERAL DISCUSSION}

The potential relationship between the results of the present experiments and reading with the Optacon may be a complicated one. An initial approach to defining the relationship might be simply to equate percent correct letter recognition to percent accuracy in reading. The variables that the present experiments show to have an effect on percent correct letter recognition would then be assumed to have the same effect on reading with the Optacon. For example, from Experiment 4, it might be assumed that increasing the space between letters in a word would increase letter recognition and that such an increase in letter recognition would lead to an increase in reading comprehension. As a matter of fact, increasing the space between letters is a technique employed by some instructors attempting to increase students' ability to identify letters with the Optacon (Brugler, Note 2). Similarly, it would be predicted, based on the results of Experiment 1, that words like "hat" and "hut" would be confused with one another in reading more often than would "cat" and "can."

It has been reported by Bliss (1974) and Hill (1974) that increasing the rate of presentation (the number of words per minute) with the Optacon results in a decrease in reading accuracy. At first glance, this result may seem to be predictable on the basis of the present masking results. Increasing the wpm rate would result in a briefer time interval between letters and, according to the results in Experiment 4, should lead to decreased letter recognition accuracy. However, an explanation of the decreased reading accuracy with increased wpm rate that relies solely or even primarily on masking may not be correct. Taenzer (1970) studied primarily the visual reading process with a device that, like the Optacon, presented letters one at a time sweeping across a screen. He varied both scan rate 
and display time. Scan rate was defined as the speed, usually measured in wpm, with which printed material passes across the screen. Display time was defined, as it is in the present study, as the amount of time a particular part of a letter is displayed. Ordinarily, a decrease in scan rate results in a decrease in display time. However, if the size of the display, specifically the number of columns, can be changed, these two variables can be manipulated independently. For example, the scan rate can be held. constant while the display time is doubled simply by doubling the number of columns in a display, e.g., from 6 to 12. Taenzer found that for visual reading observers achieved $100 \%$ comprehension when the display time was at least $150 \mathrm{msec}$. This $150-\mathrm{msec}$ figure could be achieved by several different combinations of scan rate and number of columns activated. Further, he found that one observer reading with the Optacon tended to maintain a constant $150-\mathrm{msec}$ display time by compensating for changes in display width, e.g., decreasing the scan rate when the number of columns was reduced by the experimenter from 6 to 2 . Hill (1974) found that increasing the number of columns in an Optacon display while keeping scan rate constant resulted in increased accuracy in reading. The results of the studies by Taenzer and Hill suggest that increasing scan rate decreases reading accuracy because display time is reduced. At present there are no data to suggest that varying column width as did Taenzer and Hill would have an effect on letter recognition because of masking. And, as noted above, the results from Experiment 4 show that an increase in scan rate (and a decrease in display time) causes a decrease in letter recognition accuracy even with no masking stimuli present.

Some additional data on the question of the relationship between letter recognition and masking and reading with the Optacon came from two extraordinary observers in our laboratory. The data from one of these two observers, V.B., are shown in Figure 1. As may be seen in Figure 1, V.B. showed the least change in percent correct as a function of the position of the letter. Subsequent testing showed no change in percent correct for her as a function of masking conditions, i.e., V.B. showed virtually the same percent correct for single-letter recognition as she did for recognition of letters in the presence of forward and backward maskers. A second observer showed an even higher percent correct and also showed little or no masking. What is important for a discussion of the reading process is that both of these observers, unlike our other observers, can read with the Optacon and can read at very high rates. One observer can read at better than $70 \mathrm{wpm}$ and the other at $100 \mathrm{wpm}$, the limit of the scan rate on the APS. At these rates, their comprehension for unfamiliar material is nearly $100 \%$. For our other observers, who have had the same experience with the Optacon, a scan rate of $10 \mathrm{wpm}$ allows them to pick out short words such as "and" and "the." This extremely good performance of the extraordinary observers with the Optacon seems to be highly unusual for the sighted population that we have tested and is certainly superior to the performance of most blind observers. After 2 years of experience, $85 \%$ of the Optacon users reported reading between 30 and $60 \mathrm{wpm}$ (Goldish \& Taylor, 1974). Our observers have had no formal reading training and 20 to $30 \mathrm{~h}$ of experience with the Optacon prior to their being tested on reading material. What we have is, at the present, assimple correlation. Two observers who read at very high rates with the Optacon show very little of either backward or forward masking under conditions in which the other observers, who cannot read with the Optacon, do show masking.

One final result may further indicate the complicated relationship between letter recognition and reading. One of the two extraordinary observers performs on the tasks used in the present experiments with nearly $100 \%$ accuracy. This observer reads at 70 to $80 \mathrm{wpm}$. The second observer, V.B., is not extraordinarily good at single-letter recognition. With a 90-msec display time, her single-letter recognition was $65 \%$ correct, not much different from the mean of $60 \%$ correct shown in Figure 6. However, her percent correct does not drop as the target is surrounded by masking stimuli. V.B. reads at $100 \mathrm{wpm}$. It seems to be the case that single-letter recognition accuracy is not as good a predictor of reading performance for sighted observers as accuracy in the presence of masking stimuli. A more complete description of the performance of these two observers on a number of tasks is being prepared.

\section{REFERENCE NOTES}

1. Loomis, J. M., \& Apkarian-Stielau, P. Lateral masking in tactile and blurred visual form perception. Paper presented at Psychonomic Socicty, November 1975.

2. Brugler, G. Personal communication, 1976.

\section{REFERENCES}

BÉkÉsY, G. v. Experiments in hearing. New York: McGraw-Hill, 1960.

Burss. J. C. Summary of three Optacon-related cutaneous experiments. In F. A. Geldard (Ed.), Cutaneous communication systems and devices. Austin, Tex: Psychonomic Society. 1974. Pp. 84-94.

Bliss, J. C., \& Linvill, J. G. A direct translation reading aid. In R. Dufton (Ed.). Proceedings of the Intemational Conference on Sensory Devices for the Blind. London: St. Dunstans, 1967. Pp. 389-407.

CRAIG, J. C. Difference threshold for intensity of tactile stimuli. Perception \& Psychophysics, 1972, 11, 150-152.

Craig, J. C. Attenuation of vibrotactile spatial summation. Sensory Processes, 1976, 1, 40-56.

Gisson. R. D. Vibrotactile masking: Some spatial and temporal 
aspects. Perception \& Psychophysics, 1969, 5, 176-180.

Goldish, L. H., \& TAYloR, H. E. The Optacon: A valuable device for blind persons. The New Outlook for the Blind, 1974, 68. 49-56.

HrLL, J. W. Limited field of view in reading lettershapes with the fingers. In F. A. Geldard (Ed.), Cutaneous communication systems and devices. Austin, Tex: Psychonomic Society, 1974. Pp. 95-105.

MASSARO, D. W. Experimental psychology and information processing. Chicago: Rand McNally, 1975.

Rollman, G. R. Electrocutaneous stimulation. In F. A. Geldard (Ed.), Cutaneous communication systems and devices. Austin, Tex: Psychonomic Society, 1974. Pp. 38-51.

SChIndleR, U., \& KNAPP, A. Ursachen der gegenseitigen Verdickung von taktil dargebotenen. Buchstaben: Unterbrechung, Summation, oder Verzogerung? Psychological
Research, 1976, 38, 303-318.

SHERRICK, C. E. Effects of double simultanenous stimulation of the skin. American Journal of Psychology, 1964, 77, 42-53.

TAENzer, J. C. Visual word reading. IEEE Transactions on Man-Machine Systems, 1970, MMS-11, 44-53.

\section{NOTE}

1. The Optacon (OPtical-to-TActile-CONverter) is manufactured by Telesensory Systems, Inc., Palo Alto, California.

(Received for publication May 7, 1976; revision received July 28,1976 .) 